\title{
Anisotropic creep model for soft soils
}

\author{
M. LEONI*, M. KARSTUNEN† and P. A. VERMEER*
}

In this paper a new anisotropic model for time-dependent behaviour of soft soils is presented. The formulation is based on a previously developed isotropic creep model, assuming rotated Modified Cam Clay ellipses as contours of volumetric creep strain rates. A rotational hardening law is adopted to account for changes in anisotropy due to viscous strains. Although this will introduce some new soil parameters, they do not need calibration as they can be expressed as functions of basic soil parameters through simple analytical expressions. To start with, the one-dimensional response of the model is discussed, making it possible to explore how the model is capable of capturing key features of viscous soft soil behaviour. Subsequently, the three-dimensional generalisation of the model is presented, followed by comparison with experimental data, showing good agreement in both triaxial undrained compression and extension. In the authors' opinion, the simple formulation of the model makes it attractive for use in engineering practice.

KEYWORDS: anisotropy; clays; compressibility; constitutive relations; creep; numerical modelling and analysis; time dependence
Dans la présente communication, un nouveau modèle anisotrope pour le comportement des sols meubles en fonction du temps est présenté. Cette formulation est basée sur un modèle de fluage isotrope développé précédemment avec l'hypothèse que le Modified Cam Clay devient elliptique sous forme de courbes de niveau de vitesse de déformation volumétrique. Une loi d'écrouissage rotatoire est appliquée afin de prendre en compte les changements en anisotropie dus aux déformations visqueuses. Bien que cela introduise de nouveaux paramètres relatifs au sol, ceux-ci ne nécessitent aucune calibration car ils peuvent être exprimés comme des fonctions de paramètres de base du sol à l'aide d'expressions analytiques simples. Dans un premier temps, la réponse 1D du modèle est discutée, afin d'examiner comment le modèle est en mesure de saisir les caractéristiques essentielles du comportement visqueux des sols meubles. Ensuite, la généralisation tridimensionnelle du modèle est présentée, suivie d'une comparaison avec des données expérimentales qui montre un bonne adéquation pour les compressions et extensions triaxiales en conditions non drainées. Les auteurs estiment que grâce à sa formulation simple, il s'agit d'un modèle attrayant pour des applications de type ingéniérie.

\section{INTRODUCTION}

When dealing with geotechnical design on soft soils, longterm deformations have to be considered in order to avoid future serviceability or stability problems. Strain-rate effects are also important in laboratory and field testing, and need to be taken into account in the interpretation of the results. Because of its practical importance, the creep and strain rate dependence of soft soils in general has been studied by many researchers and practitioners since the early 1920s. Many mathematical formulations of the phenomenon have been proposed, starting from the pioneering work of Buisman (1936), Bjerrum (1967) and Garlanger (1972). In most cases the proposed formulae were obtained by direct integration of differential laws of consolidation, therefore providing a useful tool that was valid for only a restricted range of cases, such as one-dimensional loading or constant effective stress.

The first simplified rheological models were developed mainly in materials science, based on simple elements such as elastic springs, plastic sliders and viscous dashpots. The model equations were usually formulated in differential form, thus allowing a basic understanding of the physical phenomenon and providing a simple tool for settlement predictions under particular boundary conditions. A further step forward was the introduction by Suklje (1957) of the isotache concept. Following this concept, many creep models

Manuscript received 16 March 2007; revised manuscript accepted 29 November 2007.

Discussion on this paper closes on 1 October 2008, for further details see p. ii.

* Institut für Geotechnik, University of Stuttgart, Germany.

$\dagger$ University of Strathclyde, UK. have been proposed, and experimental data have confirmed the validity of this approach (Den Haan, 1996; Leroueil, 2006). Experimental studies of soft soil behaviour have resulted in empirical laws that are able to model the material behaviour (Leroueil et al., 1985; Mesri \& Choi, 1985a, 1985b; Mesri \& Feng, 1986; Leroueil, 1987).

The overstress concept, first introduced by Malvern (1951) and then enhanced by Perzyna (1966), was one of the most innovative concepts in the study of viscous soil behaviour, and the basis for many general constitutive models to be used in finite element calculations. Most of those formulations were based on isotropic Cam Clay (Sekiguchi \& Ohta, 1977) or Modified Cam Clay models (Adachi \& Okano, 1974; Adachi \& Oka, 1982; Nova, 1982; Vermeer \& Neher, 1999; Yin \& Graham, 1999). A comprehensive review of creep models can be found in Liingaard et al. (2004).

Models based on isotropy may work reasonably well when dealing with reconstituted soils under fixed loading conditions. Natural soils, however, tend to exhibit anisotropy that is related to their fabric, that is, the arrangement of particles and the interparticle contacts. This affects the stress-strain behaviour of the soils in terms of viscous behaviour and deformations, and therefore needs to be taken into account. Time-dependent anisotropic models, which assume fixed anisotropy, have been proposed (e.g. Sekiguchi \& Ohta, 1977; Zhou et al., 2006). In parallel, time-independent anisotropic models accounting for both initial and evolving anisotropy have been proposed (e.g. Pestana \& Whittle, 1999; Wheeler et al., 2003; Dafalias et al., 2006). Based on Wheeler et al.'s (2003) model, a new anisotropic viscous model is proposed herein, aimed at modelling the ratedependent behaviour of normally consolidated and lightly overconsolidated soft soils. The one-dimensional formulation 
of the model is first discussed, followed by the threedimensional generalisation, resulting in the proposed anisotropic creep model. The new model, which has been implemented in a finite element code, has been validated by comparing the model response with laboratory data.

\section{ONE-DIMENSIONAL CREEP MODEL}

By first concentrating on one-dimensional compressibility of soils, the viscous behaviour of fine-grained soils can be fully investigated before describing the extension of the model to three-dimensional conditions. The one-dimensional version of the model is based on work by Vermeer and his co-workers (Stolle et al., 1997; Vermeer et al., 1998) and has some elegant features, as elaborated below.

\section{Basic equations}

As in classical elasto-plasticity, the usual decomposition of total strains into elastic and inelastic components is assumed. The elastic component is directly observed in fast unloading and recompression, whereas the other component of strain is irreversible and time dependent. In this formulation the inelastic component is assumed to be purely viscous. In terms of void ratio this implies that

$$
\dot{e}=\dot{e}^{\mathrm{e}}+\dot{e}^{\mathrm{c}}
$$

where $e$ is the void ratio; a dot over a symbol implies differentiation with respect to time; and superscripts e and c refer to the elastic and creep components respectively. In the following, the formulation is presented in terms of void ratio unless explicitly stated otherwise, and the soil mechanics sign convention (compression positive) is adopted.

The elastic change of void ratio is formulated as

$$
\dot{e}^{\mathrm{e}}=-\frac{C_{\mathrm{s}}}{\ln 10} \frac{\dot{\sigma}^{\prime}}{\sigma^{\prime}}
$$

where $\sigma^{\prime}$ is the effective stress and $C_{\mathrm{s}}$ is the swelling index. The second deformation type is due to the viscous behaviour of the material, which is modelled by the power law

$$
\dot{e}^{\mathrm{c}}=-\frac{C_{\alpha}}{\tau \ln 10}\left(\frac{\sigma^{\prime}}{\sigma_{\mathrm{p}}^{\prime}}\right)^{\beta} \quad \text { with } \quad \beta=\frac{C_{\mathrm{c}}-C_{\mathrm{s}}}{C_{\alpha}}
$$

where $C_{\alpha}$ is the well-known secondary compression index (also referred to as the creep index), $C_{\mathrm{c}}$ is the compression index, $\beta$ is the creep exponent, and $\tau$ is a reference time, which can usually be taken equal to one day, as shown in the following section.

An important soil characteristic, as observed for states of normal consolidation, concerns the normal consolidation line. On this line the preconsolidation stress $\sigma_{\mathrm{p}}^{\prime}$ increases during creep according to the differential equation

$$
\frac{\dot{\sigma}_{\mathrm{p}}^{\prime}}{\sigma_{\mathrm{p}}^{\prime}}=-\frac{\ln 10}{C_{\mathrm{c}}-C_{\mathrm{s}}} \dot{e}^{\mathrm{c}}
$$

The integrated form of this equation is

$$
\sigma_{\mathrm{p}}^{\prime}=\sigma_{\mathrm{p} 0}^{\prime} \cdot \exp \left(-\frac{\ln 10 \cdot \Delta e^{\mathrm{c}}}{C_{\mathrm{c}}-C_{\mathrm{s}}}\right), \quad \Delta e^{\mathrm{c}}=e^{\mathrm{c}}-e_{0}^{\mathrm{c}}
$$

where $\sigma_{\mathrm{p} 0}^{\prime}$ is the initial preconsolidation stress for $e^{\mathrm{c}}=e_{0}^{\mathrm{c}}$. Equation (3) is similar to the well-known creep law

$$
\dot{\varepsilon}=\alpha \cdot\left(\sigma-\sigma_{0}\right)^{\chi}
$$

introduced by Norton (1929) for metals, where $\sigma_{0}$ is a threshold stress, and $\alpha$ and $\chi$ are material constants. However, in contrast to Norton's law, $\sigma_{\mathrm{p}}^{\prime}$ in equation (3) is not a threshold stress as such, because in the proposed model creep is also assumed to take place in overconsolidated states. Because of this feature, the model cannot be simply classified as an overstress model in the sense of Perzyna (1966). In soil mechanics the concept of states with OCR > 1 is well established, but it is important to realise that states with OCR $<1$ are also possible.

To illustrate the marked effect of the overconsolidation ratio (OCR) on the creep rate, consider a typical clay of medium plasticity with $C_{\mathrm{c}}=0.15, C_{\mathrm{s}}=0.015$ and $C_{\alpha}=$ $0 \cdot 005$, giving a value of $\beta=27$ for the creep exponent in equation (3). The predicted variation of void ratio with OCR is shown in Fig. 1. It is apparent that the creep rate is almost negligible for OCR $>1.3$ for the material considered, whereas by contrast it is notable in the normally consolidated or lightly overconsolidated state. In the special case of OCR $<1$ the creep rate is very high, as indicated in Fig. 1 for $\mathrm{OCR}=0.77$. As discussed later, in a standard oedometer test with load doubled at each stage, at the end of primary consolidation OCR is between 0.5 and 1 .

\section{Logarithmic creep for $\sigma^{\prime}=$ constant}

Equation (3) holds for general states of stress and strain, as both the effective stress $\sigma^{\prime}$ and the preconsolidation stress $\sigma_{\mathrm{p}}^{\prime}$ may vary as a function of time. In fact the latter increases monotonically with creep deformation, and for a better understanding of the model it is convenient to consider the creep law with $\sigma_{\mathrm{p}}^{\prime}$ eliminated. To this end, the evolution equation (5) for $\sigma_{\mathrm{p}}^{\prime}$ is inserted into the creep law (equation (3)) to give

$$
\dot{e}^{\mathrm{c}}=-\frac{C_{\alpha}}{\tau \cdot \ln 10}\left(\frac{\sigma^{\prime}}{\sigma_{\mathrm{p} 0}^{\prime}}\right)^{\beta} \exp \frac{e^{\mathrm{c}}-e_{0}^{\mathrm{c}}}{C_{\alpha} / \ln 10}
$$

The effective stress $\sigma^{\prime}$ may be either larger or smaller than $\sigma_{\mathrm{p} 0}^{\prime}$, and it does not need to be constant. In the simplest case of creep at constant effective stress, the creep rate reduces monotonically owing to the decreasing void ratio in the exponential term.

For the special case of a constant effective stress, the differential creep law (equation (7)) can be integrated in closed form to obtain

$$
\Delta e^{\mathrm{c}}=e^{\mathrm{c}}-e_{0}^{\mathrm{c}}=-C_{\alpha} \log \left(1+\frac{t}{\tau *}\right)
$$

where $e=e_{0}$ for $t=0$ and

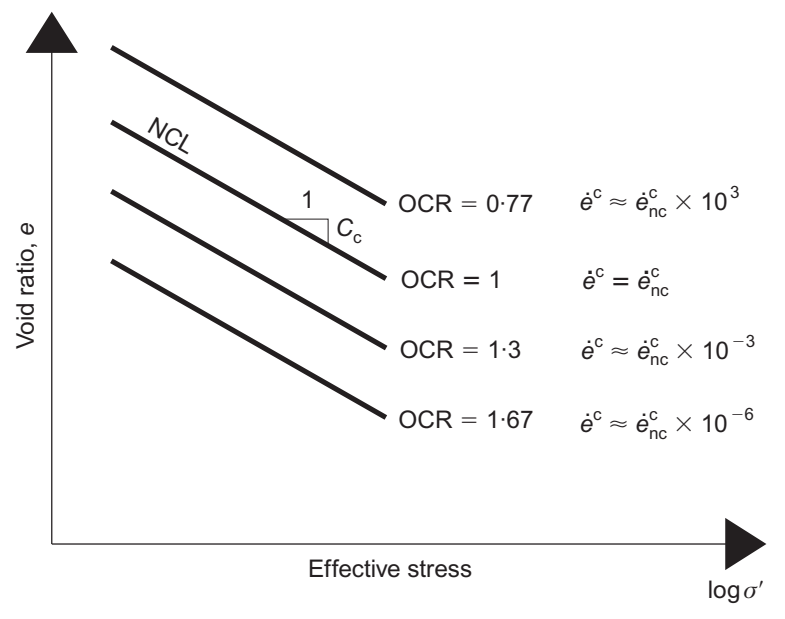

Fig. 1. Variation of creep rate with $\mathrm{OCR}$ for $\beta=27$ 


$$
\tau^{*}=\tau \cdot\left(\frac{\sigma_{\mathrm{p} 0}^{\prime}}{\sigma^{\prime}}\right)^{\beta}=\tau \cdot \mathrm{OCR}_{\mathrm{eoc}}^{\beta}
$$

where the subscript eoc indicates 'end of (primary) consolidation'.

A logarithmic creep law was first proposed by Buisman (1936), but the above form with $\tau^{*}$ was first introduced by Garlanger (1972). The reference time $\tau^{*}$ (or rather the time shift) depends completely on the initial state of overconsolidation. Consider, for example, a standard oedometer test in which the load is increased daily, as illustrated in Figs 2(a) and 2(b). Depending on the permeability of the sample, the end of consolidation may be reached in one or more hours after loading, but for the remaining part of the day the sample will creep at a constant effective stress. Equation (5) is fully valid throughout this creep period, with $t=0$ at the end of (primary) consolidation. In representing the results of an oedometer test, time is mostly reset to zero at the beginning of consolidation rather than at the end, as done in Fig. 2(b).

According to the classification of creep models by Liingaard et al. (2004), equation (8) belongs to the family of
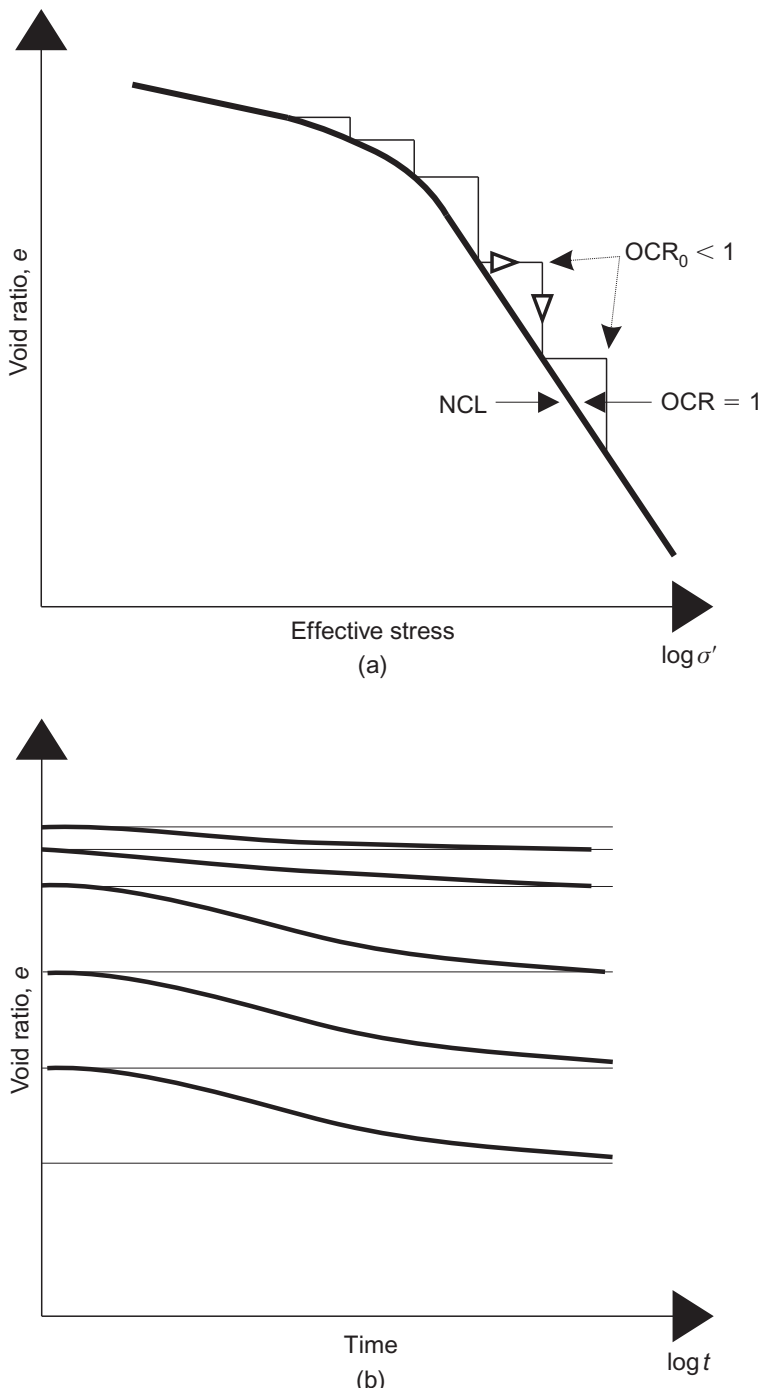

(b)

Fig. 2. Standard oedometer test with stepwise loading: (a) effective vertical stress against void ratio; (b) evolution of void ratio against time with time reset to zero for every load step empirical relations that they would classify as a 'constant $C_{\alpha}$ ' model. However, it needs to be emphasised that the reference time $\tau^{*}$ varies with OCR, as shown in equation (7), which was not discussed by Liingaard and his coauthors. In the next section the variation of the slope of $e-\log t$ curves with OCR is discussed.

\section{Overconsolidated states with $t \ll \tau^{*}$}

Consider an overconsolidated soil sample being stepwise recompressed. During recompression the sample is in a state of overconsolidation, with OCR $>1$. In this case equation (3) predicts a very low creep rate, and consequently there is very little change of OCR. This is also reflected by the logarithmic law in equation (8), as it yields

$$
\frac{\mathrm{d} e^{\mathrm{c}}}{\mathrm{d} t}=-\frac{C_{\alpha}}{\ln 10}\left(\frac{1}{\tau^{*}+t}\right) \approx-\frac{C_{\alpha}}{\ln 10} \frac{1}{\tau^{*}} \quad \text { for } t \ll \tau^{*}
$$

Indeed, for overconsolidated states of stress, the reference time $\tau^{*}$ is very large, and $t$, being approximately 1 day, is consequently small with respect to $\tau^{*}$. Hence on a usual timescale with $t \ll \tau^{*}$, as relevant in laboratory testing, overconsolidated soils show a very small, nearly constant creep rate. This behaviour is reflected by the upper set of curves in Fig. 2(b). In soil mechanics it is often suggested that even overconsolidated clays show logarithmic creep, but this is true only on a very large timescale. Indeed, it follows from equation (8) that the slopes of the curves in Fig. 2(b) satisfy the equation

$$
\frac{\mathrm{d} e^{\mathrm{c}}}{\mathrm{d} \log t}=-C_{\alpha} \cdot \frac{t}{\tau^{*}+t}
$$

If the test is run for a longer time so that $t \gg \tau *$, the behaviour will be similar to that typical for normally consolidated soil, as argued in the next section.

\section{Normally consolidated states}

In standard oedometer tests, samples are recompressed until the normal consolidation line is reached. Then the load is increased beyond the NC line, and the sample is left to consolidate and creep back to the $\mathrm{NC}$ line, as indicated in Fig. 2(a). As oedometer samples are relatively thin, consolidation is generally fast, and most of the deformation occurs at a constant effective stress. During such a creep period the overconsolidation ratio increases from the low initial value at the end of primary consolidation $\mathrm{OCR}_{\mathrm{eoc}}<1$, up to OCR $=1$. In a standard $24 \mathrm{~h}$ incremental test the load is daily doubled so that $\mathrm{OCR}_{\text {eoc }} \approx 0 \cdot 5$. In soil mechanics one is not always aware of such small OCR values. Even a proper terminology for such states is lacking. It is herein proposed to refer to it as the underconsolidated state, but it is important to realise that it does not relate just to dissipation of excess pore pressure. In such a situation of underconsolidation, equation (9) indicates that $\tau^{*}$ is extremely small, and the testing is done on a timescale with $t \gg \tau^{*}$. In this case equation (11) reduces to

$$
\frac{\mathrm{d} e^{\mathrm{c}}}{\mathrm{d} \log t} \approx-C_{\alpha} \quad \text { for } \quad t \gg \tau^{*}
$$

Therefore the creep index $\mathrm{C}_{\alpha}$ can be measured directly from load steps in the normally consolidated range. 
Meaning of reference time $\tau$ and time shift $\tau^{*}$

Whereas the use of the parameters $C_{\mathrm{c}}, C_{\mathrm{s}}$ and $C_{\alpha}$ is well established, the meaning of reference time $\tau$ may be obscure, and therefore it merits further description. Up to now it has been indicated that the reference time $\tau$ in equation (3) is mostly equal to 1 day. In this section it is shown that the reference time relates to the definition of the NC surface, and that the usual definition of this surface implies a reference time of 1 day. In order to show this, the creep in a particular load step of a conventional oedometer test is considered. On eliminating the void ratio variation $\Delta e$ between equations (5) and (8), one obtains

$$
\frac{\tau^{*}+t}{\tau^{*}}=\left(\frac{\sigma_{\mathrm{p}}^{\prime}}{\sigma_{\mathrm{p} 0}^{\prime}}\right)^{\beta}
$$

Together with equation (9) for $\tau^{*}$ it is found that

$$
\mathrm{OCR}=\left(\frac{\tau^{*}+t}{\tau}\right)^{1 / \beta}
$$

For normally consolidated states $\tau^{*}$ is very small, as already argued in the previous section. Then equation (14) reduces to the very simple expression

$$
\mathrm{OCR} \approx\left(\frac{t}{\tau}\right)^{1 / \beta} \text { for } t \gg \tau^{*}
$$

which was first put forward by Mesri \& Choi (1985a). Hence OCR will rapidly increase from its initial small value of $\mathrm{OCR}_{\text {eoc }}$ up to $\mathrm{OCR}=1$. In oedometer testing the load is most often increased every $24 \mathrm{~h}$, and consolidation takes typically a few hours. In such a test the creep time for reaching the normal consolidation line would be around $20 \mathrm{~h}$ or roughly 1 day. On substituting $\mathrm{OCR}=1$ and $t=1$ day into equation (15), one obtains $\tau=1$ day. No doubt oedometer tests may also be carried out with $12 \mathrm{~h}$ or $48 \mathrm{~h}$ load steps to find somewhat shifted NC lines with $\tau=12$ or $\tau=$ $48 \mathrm{~h}$ respectively. It is worth mentioning that the value assumed for preconsolidation pressure is related to the duration of the test, and a different testing time would lead to different values.

\section{Constant rate of strain test}

Instead of defining the normal consolidation line of a particular clay on the basis of a multi-stage loading test, one may use a constant rate of strain test. Data by Hanzawa (1989) in Fig. 3 demonstrate that these so-called CRS tests give oedometer curves that resemble those of multi-stage loading tests (MSL). CRS tests are done relatively quickly, and the results tend to overshoot the NC line from a $24 \mathrm{~h}$ MSL test, as can be seen in Fig. 3. However, any CRS test line can be adopted as the NC line, provided that an appropriate reference time $\tau$ is assigned to this line, as will be shown in the following. Considering a CRS test with a particular constant rate of change of void ratio, it follows from equations (1), (2) and (4) that

$$
\dot{e}=\dot{e}^{\mathrm{e}}+\dot{e}^{\mathrm{c}}=-\frac{C_{s}}{\ln 10} \frac{\dot{\sigma}^{\prime}}{\sigma^{\prime}}-\frac{C_{\mathrm{c}}-C_{\mathrm{s}}}{\ln 10} \frac{\dot{\sigma}_{\mathrm{p}}^{\prime}}{\sigma_{\mathrm{p}}^{\prime}}
$$

It can be shown that $\dot{\sigma}^{\prime} / \sigma^{\prime}=\dot{\sigma}_{\mathrm{p}}^{\prime} / \sigma_{\mathrm{p}}^{\prime}$, and from this it follows that the elastic strain rate is given by $C_{\mathrm{s}} /\left(C_{\mathrm{c}}-C_{\mathrm{s}}\right)$ times the creep rate. This can be used to write

$$
\dot{e}=\frac{C_{\mathrm{c}}}{C_{\mathrm{c}}-C_{\mathrm{s}}} \cdot \dot{e}^{\mathrm{c}}=-\frac{C_{\mathrm{c}}}{C_{\mathrm{c}}-C_{\mathrm{s}}} \cdot \frac{C_{\alpha}}{\tau \cdot \ln 10}\left(\frac{\sigma^{\prime}}{\sigma_{\mathrm{p}}^{\prime}}\right)^{\beta}
$$

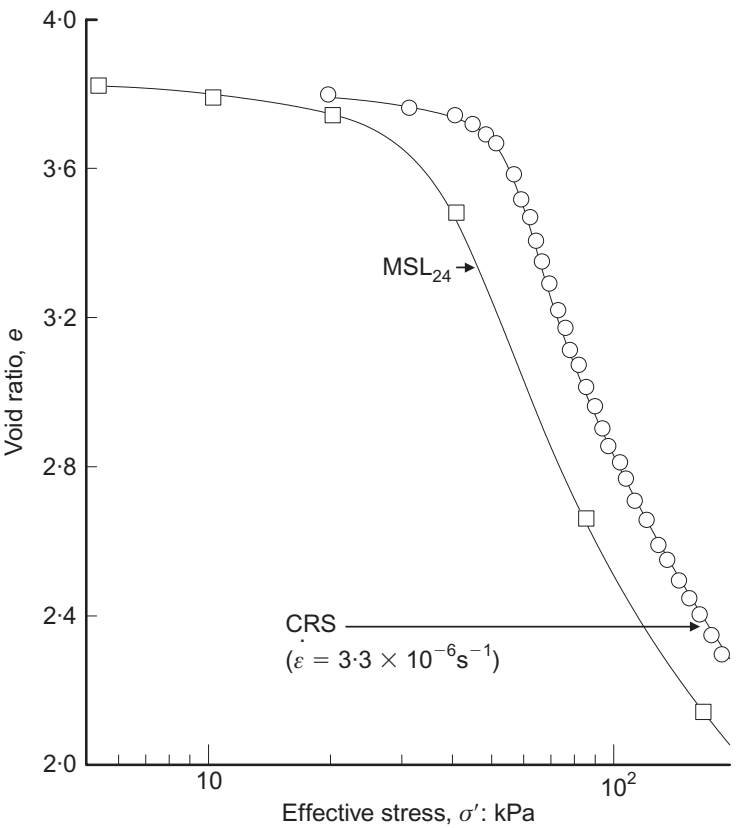

Fig. 3. Stress-strain curves obtained in conventional $24 \mathrm{~h}$ test and CRS oedometer (after Hanzawa, 1989)

For $\sigma^{\prime}=\sigma_{\mathrm{p}}^{\prime}$ we are on the NC line, and consequently

$$
\dot{e}_{\mathrm{nc}}^{\mathrm{c}}=-\frac{C_{\mathrm{c}}}{C_{\mathrm{c}}-C_{\mathrm{s}}} \cdot \frac{C_{\alpha}}{\tau \ln 10}
$$

If $\tau$ is assumed to be 1 day, the CRS test has to be carried out at the appropriate rate according to equation (18). On the other hand, one may also adjust $\tau$ to any possible CRS test. This is clear if equation (18) is rewritten as

$$
\tau=-\frac{C_{\mathrm{c}}}{C_{\mathrm{c}}-C_{\mathrm{s}}} \cdot \frac{C_{\alpha}}{\ln 10} \cdot \frac{1}{\dot{e}_{\mathrm{nc}}}
$$

where $C_{\alpha}$ has to be measured in a real creep test with constant effective stress. On taking the NC line from a CRS test, the applied deformation rate is assumed to be $\dot{e}_{\mathrm{nc}}$ and the corresponding reference time may be computed from equation (19).

\section{THREE-DIMENSIONAL ISOTROPIC CREEP MODEL}

The one-dimensional formulation was extended to a general three-dimensional constitutive model based on Modified Cam Clay type ellipses by Vermeer and his co-workers (Vermeer et al., 1998). The model was tested on drained and undrained compression tests on reconstituted soils, showing an overall good performance (Vermeer \& Neher, 1999). Nevertheless, the assumption of isotropic yield surfaces does not match experimental evidence for natural soils, as shown in Fig. 4. Skewed yield surfaces have been observed for a wide range of soft soils, and are a reflection of initial anisotropy. The anisotropy has been created by the mechanism of deposition, the shapes of the particles, and any subsequent loading, often involving one-dimensional consolidation under the soil's self-weight. It has also been shown that the initial anisotropy can be erased if the material is subjected to isotropic straining (Anandarajah et al., 1996; Bai \& Smart, 1996; Wheeler et al., 2003). A more realistic constitutive model must take the initial anisotropy of the natural soil into account, as well as its evolution due to irrecoverable straining. 


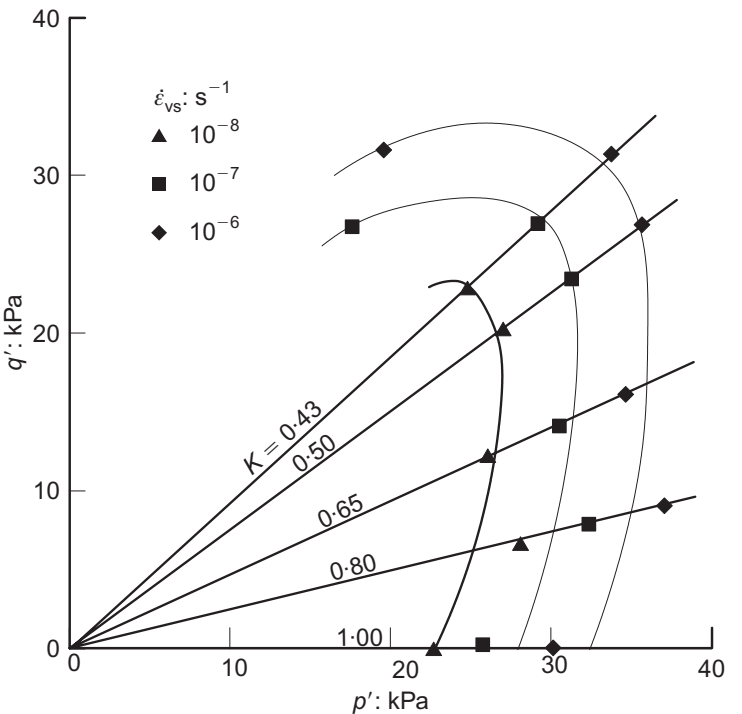

Fig. 4. Contours of volumetric creep strain rate for a natural soil (after Boudali, 1995)

\section{ANISOTROPIC CREEP MODEL}

In order to match the creep rate contours shown in Fig. 4, the yield surface of the so-called S-CLAY1 model by Wheeler et al. (2003) is adopted as the normal consolidation surface for the anisotropic creep model; see Fig. 5. With evolution of anisotropy, the use of classical stress invariants for defining this surface is no longer possible. The simplest way is to define these surfaces in terms of the deviatoric stress tensor and mean effective stress (the so-called mixed formulation) in conjunction with a deviatoric fabric tensor that describes the arrangement of fabric. The full formulation can be found in the Appendix.

\section{Basic equations}

Most experimental testing, however, is done on samples that are cross-anisotropic: that is, on samples that have been cut vertically from the ground. Because the stress axes in triaxial and oedometer tests are fixed, a cross-anisotropic material will stay cross-anisotropic throughout a test. In this special case, the expression for the normal consolidation surface (NCS) can be simplified, and it is still possible to make use of the well-known stress invariants $p^{\prime}$ and $q$, the

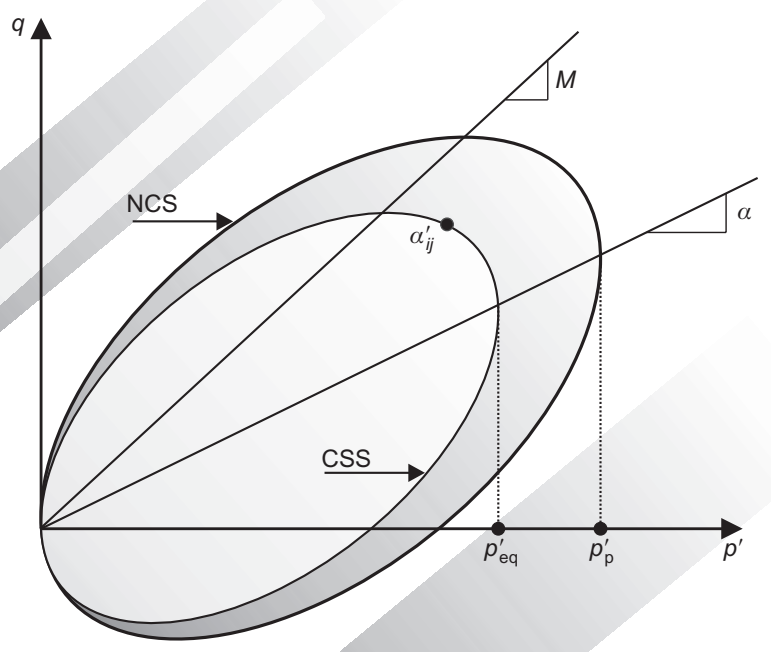

Fig. 5. Anisotropic creep model: current state surface (CSS) and normal consolidation surface (NCS) in triaxial stress space mean effective stress and deviatoric stress. Adopting the summation convention, the stress invariants $p^{\prime}$ and $q$ are defined as

$$
p^{\prime}=\sigma_{\mathrm{ii}}^{\prime} / 3, \quad q=\frac{3}{2} \sqrt{s_{i j} \cdot s_{i j}}
$$

where $s_{i j}$ is the well-known deviatoric stress tensor.

In this particular case, a scalar quantity $\alpha$ (see the Appendix) can be used to describe the orientation of the normal consolidation surface. In order to do so, a so-called equivalent mean stress $p_{\text {eq }}^{\prime}$ is defined as

$$
p_{\mathrm{eq}}^{\prime}=p^{\prime}+\frac{\left(q-\alpha \cdot p^{\prime}\right)^{2}}{\left(M^{2}-\alpha^{2}\right) \cdot p^{\prime}}
$$

where $M$ is the stress ratio at critical state. The normal consolidation surface is now defined as $p_{\mathrm{eq}}^{\prime}=p_{\mathrm{p}}^{\prime}$, where $p_{\mathrm{p}}^{\prime}$ is the preconsolidation pressure, as illustrated in Fig. 5. Strictly speaking, the new surface should be referred to as a sheared ellipse. However, for the sake of simplicity, the word 'rotation' is used herein. Different values of $M$ can be assumed in triaxial compression and extension by changing the values of $M$ as $(\eta-\alpha)$ goes from positive to negative, as discussed by Wheeler et al. (2003). The same form as equation (20) has been adopted by Zhou et al. (2006) for their viscoplastic model.

The preconsolidation pressure $p_{\mathrm{p}}^{\prime}$ evolves with volumetric creep strains $\varepsilon_{\mathrm{vol}}^{\mathrm{c}}$ according to the hardening law

$$
p_{\mathrm{p}}^{\prime}=p_{\mathrm{p} 0}^{\prime} \cdot \exp \left(-\frac{\varepsilon_{\mathrm{vol}}^{\mathrm{c}}}{\lambda^{*}-\kappa^{*}}\right)
$$

where $\lambda^{*}=\lambda /\left(1+e_{0}\right)$ and $\kappa^{*}=\kappa /\left(1+e_{0}\right)$ are the modified compression and swelling indexes respectively. When $p_{\mathrm{eq}}^{\prime}=p_{\mathrm{p}}^{\prime}$ the current stress lies on the normal consolidation surface (Fig. 5), and the soil state is normally consolidated. The ratio $p_{\mathrm{p}}^{\prime} / p_{\mathrm{eq}}^{\prime}$, referred to as $\mathrm{OCR}^{*}$, gives a measurement of the distance between the current stress surface and the normal consolidation surface, being a generalisation of OCR (the vertical overconsolidation ratio). By formulating the volumetric strain rate in terms of strains, equation (3) becomes

$$
\dot{\varepsilon}_{\mathrm{vol}}^{\mathrm{c}}=\frac{\mu^{*}}{\tau}\left(\frac{1}{\mathrm{OCR}^{*}}\right)^{\beta} \quad \text { where } \quad \mu^{*}=\frac{C_{\alpha}}{\ln 10\left(1+e_{0}\right)}
$$

$\mu^{*}$ is referred to as the modified creep index. The deviatoric component of the creep strain rate vector results simply from the flow rule, which for the sake of simplicity is assumed as associated.

\section{Rotational hardening law}

The scalar quantity $\alpha$ in equation (21) acts like a rotational hardening parameter, and its evolution is governed by creep strains according to the rotational hardening

$$
\dot{\alpha}=\omega\left[\left(\frac{3 q}{4 p^{\prime}}-\alpha\right) \dot{\varepsilon}_{\mathrm{vol}}^{\mathrm{c}}+\omega_{\mathrm{d}}\left(\frac{q}{3 p^{\prime}}-\alpha\right) \dot{\gamma}^{\mathrm{c}}\right]
$$

where $\dot{\gamma}^{\mathrm{c}}$ is the deviatoric creep strain rate, defined as $\dot{\gamma}^{c}=\frac{2}{3}\left|\dot{\varepsilon}_{1}^{c}-\dot{\varepsilon}_{2}^{c}\right|$ for triaxial states of stress. The soil constants $\omega$ and $\omega_{\mathrm{d}}$ that control the rate of rotation are related to basic soil parameters, as discussed in subsequent sections. Experimental evidence for equation (24) has been put forward by Näätänen et al. (1999) and Wheeler et al. (2003). It is worth noting that in the model proposed by Zhou et al. (2006) anisotropy is assumed to stay fixed, with $\dot{\alpha}=0$, in contrast to experimental evidence. The simulations later on 
in this paper also demonstrate the need for a rotational hardening law, and in particular for modelling strains in triaxial extension.

\section{Initial condition $\alpha_{0}$ and parameter $\omega_{\mathrm{d}}$}

As commonly assumed in geomechanics, and supported by ample experimental evidence, an estimate of $K_{0}$ for normally consolidated soils is provided by Jaky's formula

$$
K_{0}^{\mathrm{NC}} \approx 1-\sin \phi_{\mathrm{cv}}^{\prime}
$$

where $\phi_{\mathrm{cv}}^{\prime}$ is the critical-state friction angle.

Provided that the soil has been one-dimensionally consolidated, a correlation between $K_{0}^{\mathrm{NC}}$ and the initial rotation of the ellipse, $\alpha_{0}$, is evident. Assuming an associated flow rule, and considering that in one-dimensional loading the ratio between deviatoric and volumetric plastic strain rates is approximately $\frac{2}{3}$, it follows that (Wheeler et al., 2003)

$$
\alpha_{0}=\frac{\eta_{0}^{2}+3 \eta_{0}-M^{2}}{3}
$$

where $\eta_{0}=3\left(1-K_{0}^{\mathrm{NC}}\right) /\left(1+2 K_{0}^{\mathrm{NC}}\right)$ and $M=6 \sin \phi_{c v}^{\prime} /$ $\left(3-\sin \phi_{c v}^{\prime}\right)$. Moreover, Wheeler et al. (2003) show that

$$
\omega_{\mathrm{d}}=\frac{3}{8} \frac{4 M^{2}-4 \eta_{0}^{2}-3 \eta_{0}}{\eta_{0}^{2}-M^{2}+2 \eta_{0}}
$$

Therefore the initial inclination $\alpha_{0}$ and the shear rotation parameter $\omega_{\mathrm{d}}$ are fully determined by the critical-state angle, and do not need any calibration. When the values for model parameters have been derived this way, the model implicitly gives realistic $K_{0}$ prediction, in contrast to viscoplastic models using Modified Cam Clay ellipses.

\section{Rate of rotation $\omega$}

The parameter $\omega$ controls the absolute rate at which the normal consolidation surface rotates with viscous straining. A similar parameter is found in anisotropic models by Pestana \& Whittle (1999) and Dafalias et al. (2006). They also suggested procedures and/or laboratory tests to calibrate this rotation parameter. Zentar et al. (2002) simply suggested $\omega$ to be a function of the compression index $\lambda$, so that calibration is not required.

In the following a relation between $\omega$ and $\lambda^{*}$ will be derived. Experimental evidence shows that the initial anisotropy is erased in isotropic loading up to a pressure that is two or three times larger than the preconsolidation pressure (Anandarajah et al., 1996). The volumetric strain for erasing the anisotropy is thus

$$
\Delta \varepsilon_{\mathrm{vol}}^{\mathrm{c}}=\left(\lambda^{*}-\kappa^{*}\right) \ln \frac{p_{\mathrm{p}}^{\prime}}{p_{\mathrm{p} 0}^{\prime}}=\left(\lambda^{*}-\kappa^{*}\right) \ln (2 \ldots 3) \approx \lambda^{*}
$$

The ratio between deviatoric and volumetric strain rates is given by the flow rule

$$
\frac{\dot{\gamma}^{\mathrm{c}}}{\dot{\varepsilon}_{\mathrm{vol}}^{\mathrm{c}}}=\frac{\partial p_{\mathrm{eq}}^{\prime} / \partial q}{\partial p_{\mathrm{eq}}^{\prime} / \partial p^{\prime}}=\frac{2\left(q / p^{\prime}-\alpha\right)}{M^{2}-\left(q / p^{\prime}\right)^{2}}
$$

Substituting equation (29) into equation (24), and considering isotropic loading with $q=0$, leads to the differential equation

$$
\frac{M^{2} \dot{\alpha}}{M^{2} \alpha-2 \alpha^{2} \omega_{\mathrm{d}}}=-\omega \dot{\varepsilon}_{\mathrm{vol}}^{\mathrm{c}}
$$

This differential equation can be integrated in the range between $\alpha_{0}$ and $\alpha=\alpha_{0}+\Delta \alpha$ to obtain

$$
\ln \frac{\alpha_{0} / \alpha-2 \alpha_{0} \omega_{\mathrm{d}}}{M^{2}-2 \alpha_{0} \omega_{\mathrm{d}}}=\omega \Delta \varepsilon_{\mathrm{vol}} \approx \omega \lambda^{*}
$$

Assuming that anisotropy is practically erased when $\alpha$ decreases to $1 / 10$ th of its initial value, which means $\alpha_{0} / \alpha=$ 10 , equation (31) can be solved with respect to $\omega$ to give

$$
\omega=\frac{1}{\lambda^{*}} \ln \frac{10 M^{2}-2 \alpha_{0} \omega_{\mathrm{d}}}{M^{2}-2 \alpha_{0} \omega_{\mathrm{d}}}
$$

where $\alpha_{0}$ and $\omega_{\mathrm{d}}$ are fully determined by the critical-state angle, as specified by equations (26) and (27) respectively. Hence $\omega$ depends exclusively on the modified compression index $\lambda^{*}$ and on the critical friction angle. Therefore the value for parameter $\omega$ can be conveniently estimated via equation (32) with no need for calibration.

\section{Undrained shear strength}

The capability of the isotropic creep model to simulate the strain-rate dependence in drained triaxial compression tests has already been shown by Vermeer \& Neher (1999). For triaxial compression the new anisotropic model behaves in a very similar manner, since the rotation induced by shearing in compression is not that significant if starting from a $K_{0}$-consolidated state. In the following, only undrained triaxial test simulations are considered, and attention is focused mostly on extension tests.

The material chosen for a first set of simulations is Haney clay. Most material data shown in Table 1 are derived on the basis of experimental data by Vaid \& Campanella (1977). The value of $\omega$ was estimated from equation (32), and the initial rotations $\alpha_{0}$ and $\omega_{\mathrm{d}}$ were computed using equations (26) and (27) respectively. Simulations are carried out starting from a normally consolidated state with $K_{0}^{\mathrm{NC}}$ estimated as 0.47 through Jaky's formula. Starting from a vertical effective stress of $160 \mathrm{kPa}$ the soil is sheared to failure in compression, as well as in extension, using two different strain rates: the usual fast strain rate of $1 \% / \mathrm{h}$, and a slow rate of $0.05 \% / \mathrm{h}$. The aim of this first set of analyses is to inspect the differences between the rate-independent elastoplastic S-CLAY1 model and the new anisotropic creep model.

The computed stress paths as depicted in Fig. 6 show the typical influence of strain rate: the slower the test, the flatter the stress path. For the slow test the present viscous model shows good agreement with the elasto-plastic S-CLAY1 model. However, the resulting undrained shear strengths are somewhat different, as also shown in Fig. 7. For the range of strain rates considered, all extension simulations show more or less the same stiffness, but the behaviour in compression is considerably different.

In addition to the strain rates $1 \% / \mathrm{h}$ and $0.05 \% / \mathrm{h}$ considered so far, an undrained compression test with the rate of $20 \% / \mathrm{h}$ was simulated. Considering these strain rates, ranging from $0.05 \%$ to $20 \%$, the results are well approximated by the equation

Table 1. Values for soil parameters and initial inclination $\alpha_{0}$ for Haney clay

\begin{tabular}{l|c|c|c|c|c|c|c}
\hline$\lambda^{*}$ & $\kappa^{*}$ & $\mu^{*}$ & $v^{\prime}$ & $M_{\mathrm{c}}$ & $\omega$ & $\omega_{\mathrm{d}}$ & $\alpha_{0}$ \\
\hline 0.1055 & 0.0161 & 0.0044 & 0.255 & 1.29 & 28 & 0.856 & 0.493 \\
\hline
\end{tabular}




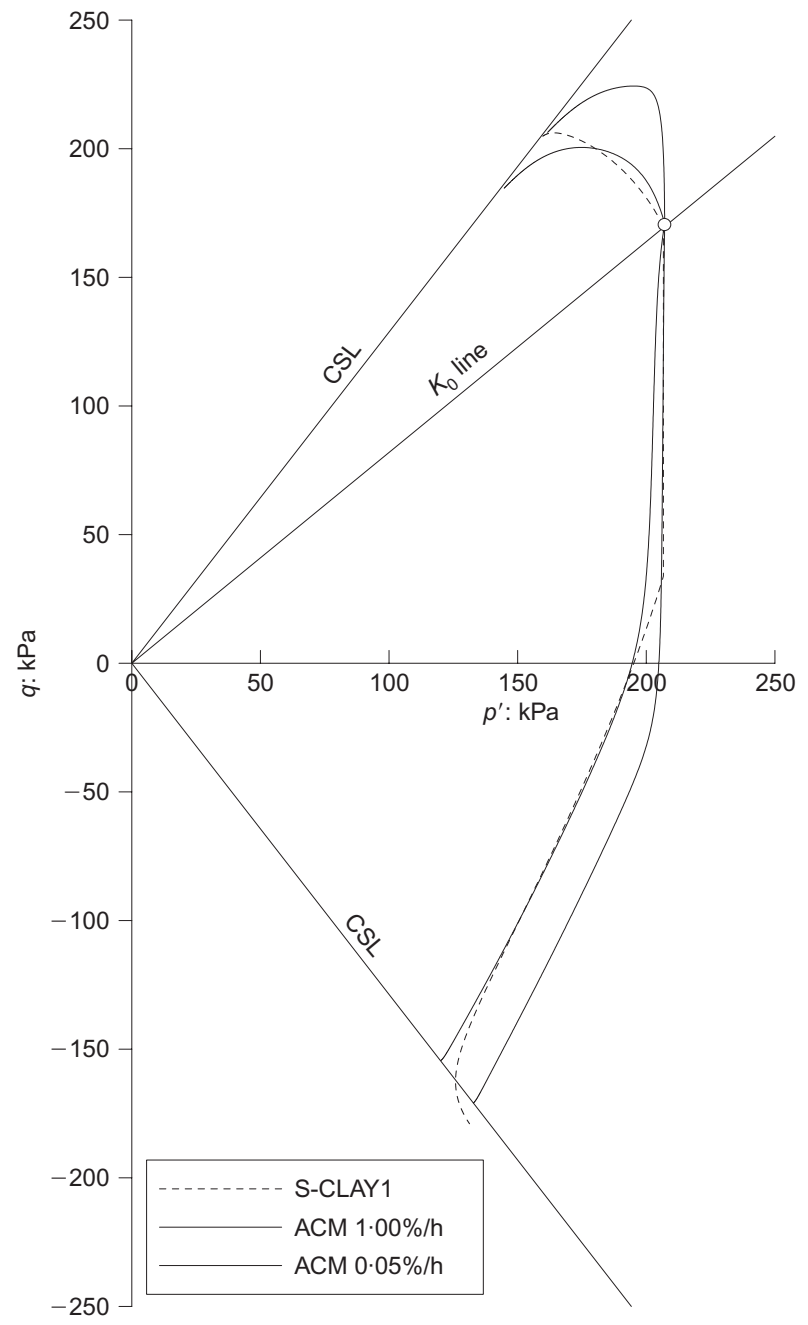

Fig. 6. Haney clay. Predicted stress paths in undrained triaxial compression and extension: S-CLAY1 against the anisotropic creep model (ACM)

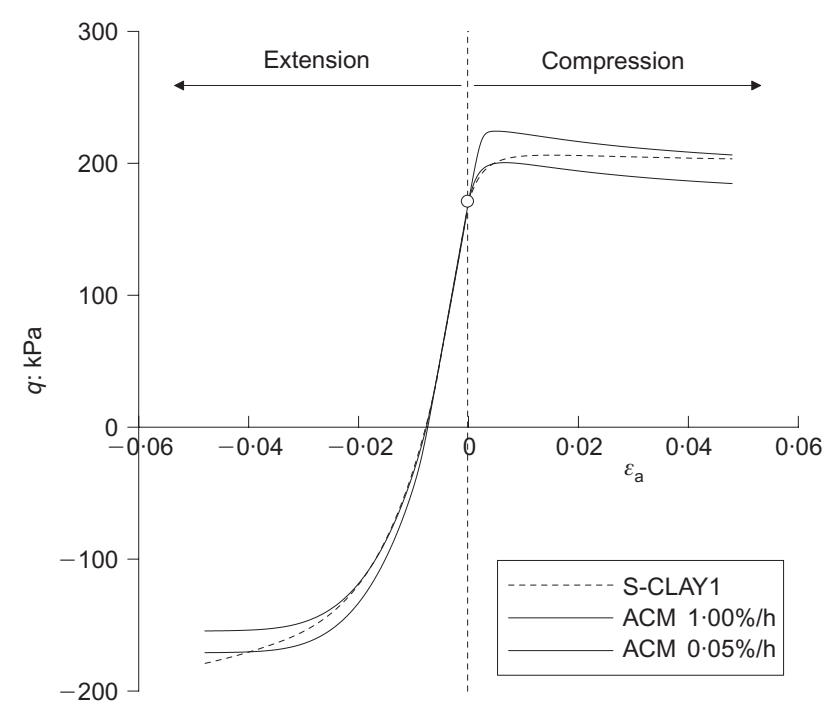

Fig. 7. Haney clay. Predicted stress-strain behaviour for undrained compression and extension: S-CLAY1 against the anisotropic creep model (ACM)

$$
\frac{c_{\mathrm{u}}}{c_{\mathrm{u} 1 \% / \mathrm{h}}}=1.00+0.09 \log \dot{\varepsilon}
$$

shown in Fig. 8. This is in close agreement with the experimental data compiled by Kulhawy \& Mayne (1990).

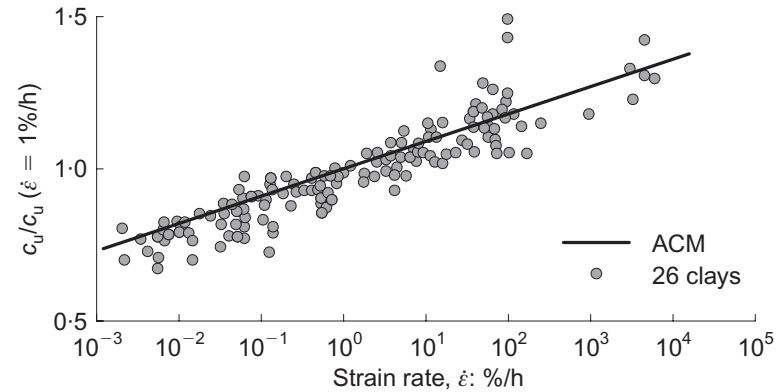

Fig. 8. Undrained shear strength in undrained triaxial compression (data after Kulhawy \& Mayne, 1990)

During both compression and extension tests the normal consolidation surface rotates, as expressed by a change of $\alpha$. In triaxial compression tests $\alpha$ decreases very slightly, if shearing starts from a $K_{0}$-consolidated state. For the extension tests, on the other hand, Fig. 9 shows a remarkable decrease of the $\alpha$-value from 0.49 down to $-0 \cdot 2$, towards the asymptotic value of $M_{\mathrm{c}} / 3=-0.43$ at very large strains. All simulations show nearly the same rotation of the normal consolidation surface. Hence it would seem that the rotation is virtually independent of the applied strain rate. The rateindependent S-CLAY1 model predicts the same amount of rotation as the viscous model.

Comparison with extension test data

In a second set of analyses the response of the anisotropic model, as well as its isotropic version, is compared with laboratory data. As for the material, Hong Kong Marine Deposit is considered, using the test data by Yin \& Cheng (2006). As reported by Yin \& Cheng, the material is a dark grey clayey silt with some shells, with liquid limit $w_{\mathrm{L}}=$ $57 \%$, plastic limit $w_{\mathrm{P}}=25 \%$, and average water content before testing of $w=54.3 \% . K_{0}^{\mathrm{NC}}$ was chosen as 0.48 according to Jaky's formula. The full dataset used for the analyses is summarised in Table 2. This set of soil parameters was directly provided by Yin \& Cheng (2006), with the exception of the rotational parameters $\omega_{\mathrm{d}}$ and $\omega$, which were evaluated from equations (27) and (32) respectively. It is worth noting that different slopes of the critical-state line have been assumed in compression $\left(M_{\mathrm{c}}\right)$ and in extension $\left(M_{\mathrm{e}}\right)$. On performing the numerical analyses, the procedure described by Yin \& Cheng for the laboratory tests was fully

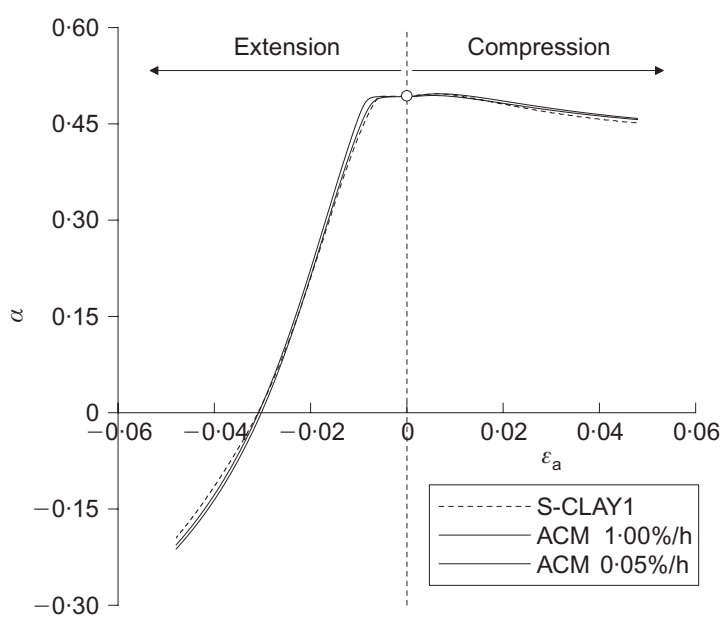

Fig. 9. Haney clay. Predicted evolution of $\alpha$ for undrained compression and extension: S-CLAY1 against the anisotropic creep model (ACM) 
Table 2. Values for soil parameters and initial inclination $\alpha_{0}$ for Hong Kong Marine Deposit

\begin{tabular}{c|c|c|c|c|c|c|c|c}
\hline$\lambda^{*}$ & $\kappa^{*}$ & $\mu^{*}$ & $M_{\mathrm{c}}$ & $M_{\mathrm{e}}$ & $v^{\prime}$ & $\omega$ & $\omega_{\mathrm{d}}$ & $\alpha_{0}$ \\
\hline 0.07933 & $0 \cdot 0188$ & $0 \cdot 00254$ & $1 \cdot 2431$ & $0 \cdot 879$ & $0 \cdot 25$ & $43 \cdot 15$ & $0 \cdot 807$ & $0 \cdot 474$ \\
\hline
\end{tabular}

simulated. The specimen was first consolidated following the $K_{0}^{\mathrm{NC}}$ line and then sheared at an axial strain rate of $2 \% / \mathrm{h}$ in undrained conditions, both in compression and in extension. In this paper the original denomination is used, so that the two sets of tests considered are referred to as E150 and E400.

The comparisons between predicted and experimental stress paths are plotted in Fig. 10. The anisotropic model is in good agreement with the experiments, even if the final effective mean stress is larger (as an absolute value) than the one measured in the laboratory. The final inclination of the path is captured well, and if one were to prolong the experimental test until the critical state was reached, the predicted undrained shear strength would match the measured one. By contrast, the isotropic model shows its inadequacy when modelling undrained extension tests. As shown in Fig. 10, the (mainly) elastic region is too large, and only when the stress path is already close to critical state does $p^{\prime}$ start to decrease towards the critical-state line. Moreover, the undrained shear strength is clearly exceeded.

The stress-strain plots obtained by using the anisotropic model are compared with measurements in Fig. 11 and Fig. 12 for E150 and E400 respectively: numerical results deviate slightly from experimental data, as the real soil appears to be stiffer within the predominantly elastic range. No doubt this problem could be fixed by implementing a small-strain

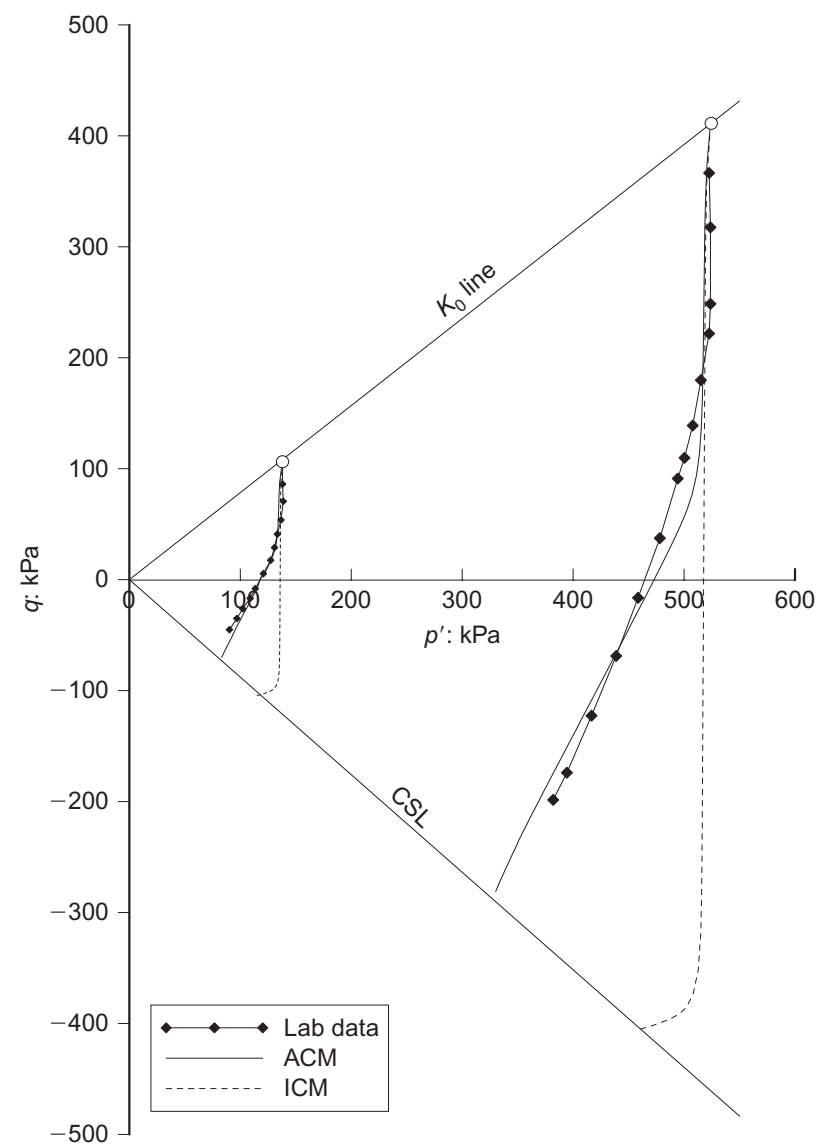

Fig. 10. Hong Kong Marine Deposit: stress paths for undrained extension tests E150 and E400 (data from Zhou et al., 2006)

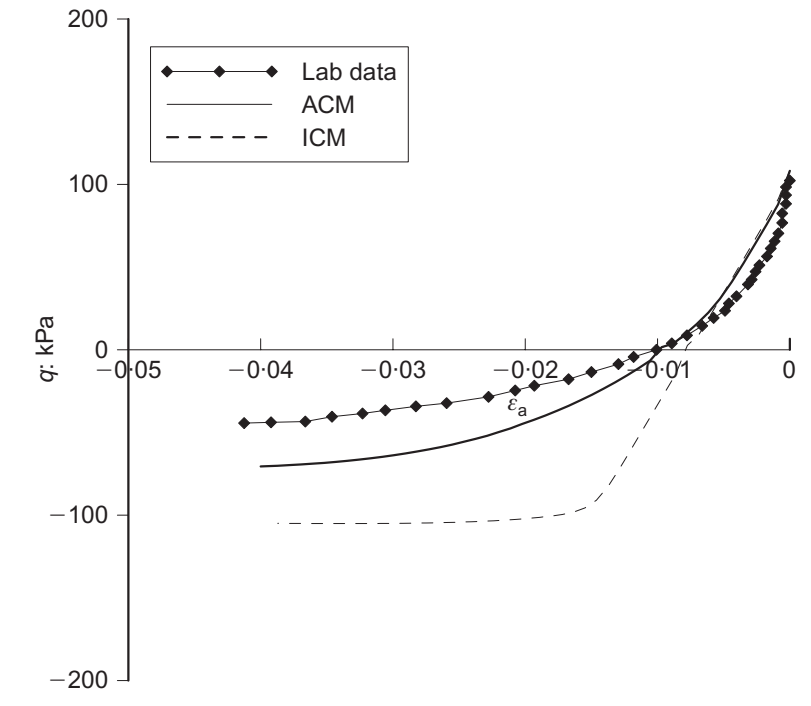

Fig. 11. Hong Kong Marine Deposit: deviatoric stress against axial strain in undrained extension test E150 (data from Zhou et al., 2006)

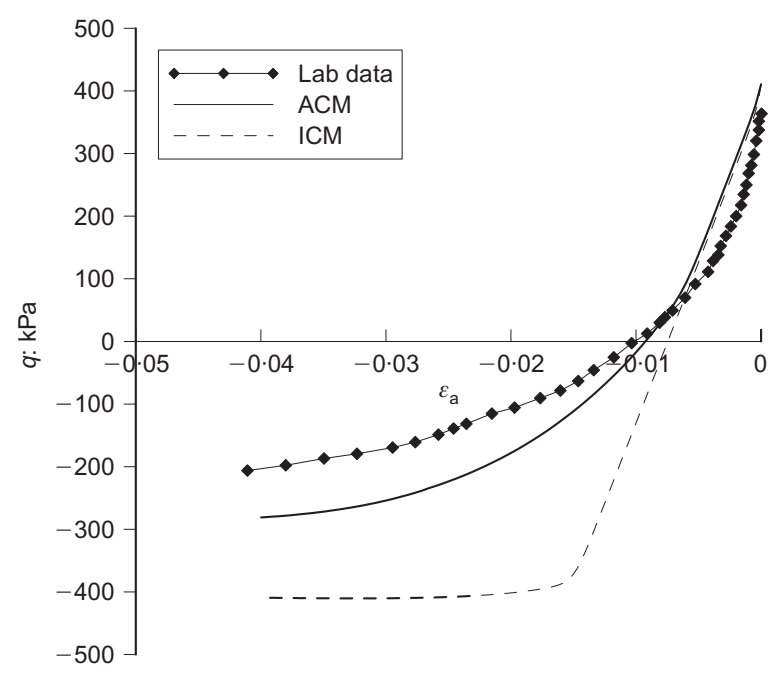

Fig. 12. Hong Kong Marine Deposit; deviatoric stress against axial strain in undrained extension test E400 (data from Zhou et al., 2006)

stiffness in the constitutive model. On the other hand, when the strain becomes large, the predicted stiffness is too high, thus giving a larger prediction of the undrained shear strength than the experiment indicates for the same final strain of $4 \%$. The poor prediction of the isotropic model already shown in Fig. 10 is reflected in the stress-strain behaviour of Figs 11 and 12: its predictions are far from the measurements, from both a qualitative and a quantitative point of view. Note that the S-CLAY1 model would predict the same undrained strength as the viscous model, but only if the strain rate in the test was very low (see Fig. 6).

The results obtained with the anisotropic model are very encouraging, especially in view of the fact that the match is achieved without needing to calibrate any material parameters in addition to those already used in the isotropic model.

\section{Importance of rotational hardening}

It is worth investigating the importance of having a rotational hardening law when modelling anisotropy. Indeed, 
it is used in existing elasto-plastic models, but not as yet in creep models. Therefore another simulation is performed by setting the rate of the rotation parameter $\omega$ equal to 0 , thus fixing the normal consolidation surface to its initial rotated state, as assumed by Zhou et al. (2006). The results for the E400 test are shown in Fig. 13 as for the predicted stress path, and Fig. 14 shows the predictions of deviatoric stress against axial strain. From the latter, one might conclude that the model with a fixed surface is giving better predictions, but this is just coincidence, as the observation of Fig. 13 demonstrates that the predicted stress path is far from the measured one. Consequently, the predicted undrained strength in triaxial extension is far too low. The anisotropic elasto-plastic model S-CLAY1 would predict a stress path qualitatively similar to the viscous model, as illustrated in Fig. 6, provided that the strain rate was low.

By contrast, the prediction with fixed anisotropy is qualitatively very different, and far from the experimental results. This demonstrates that coupling a viscous formulation with anisotropy must be accompanied by a suitable evolution law for anisotropy as a function of viscous strains in order to predict the undrained shear strength correctly, both in triaxial extension and in compression.

To complete the investigation into the effectiveness of the anisotropic creep model, a comparison of the stress path obtained in an undrained compression test on Hong Kong Marine Deposit is shown in Fig. 15, and the deviatoric stress is plotted against axial strain in Fig. 16. As for the previous tests, the rate of axial strain was $2 \% / \mathrm{h}$, and the initial stress was set to lie on the $K_{0}^{\mathrm{NC}}$ line. The numerical simulation has been stopped at the same vertical strain value as the laboratory test indicates. The agreement between numerical analysis and measurements is excellent. In particular, the

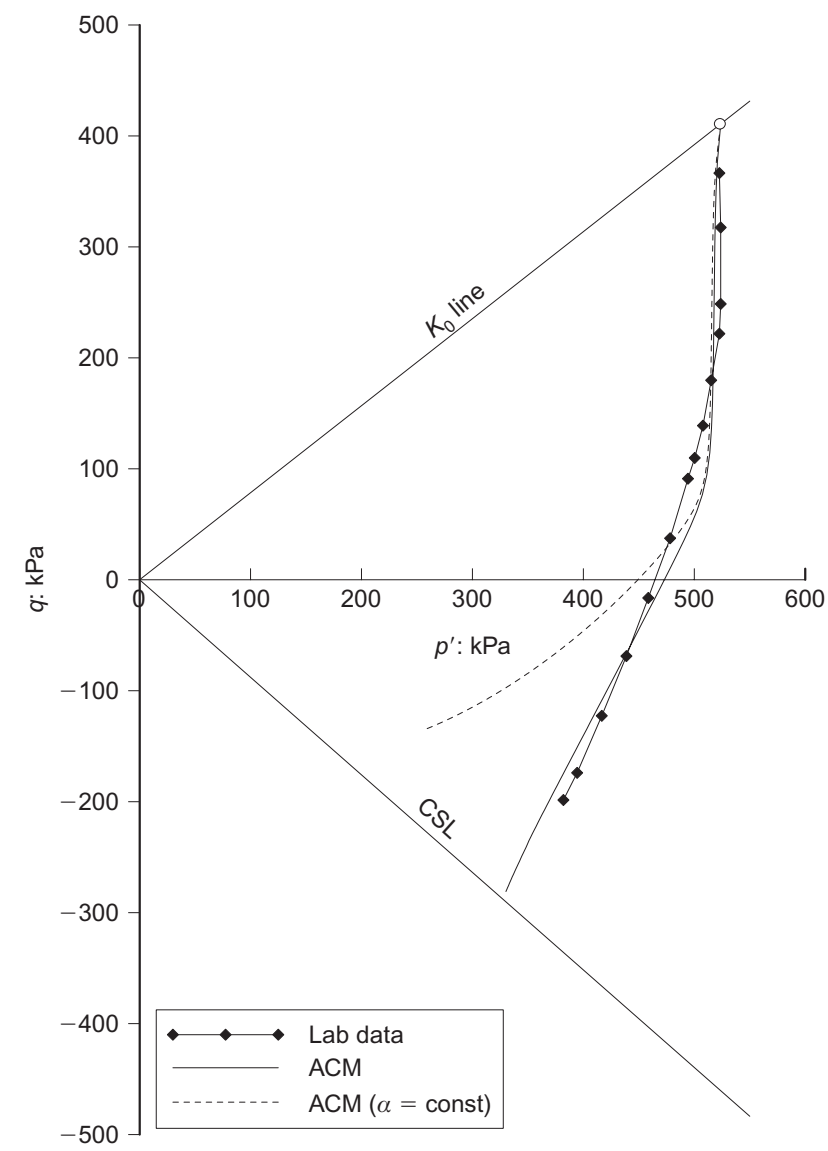

Fig. 13. Hong Kong Marine Deposit: effect of rotational hardening on stress path prediction for test $\mathbf{E} 400$ (data from Zhou et al., 2006)

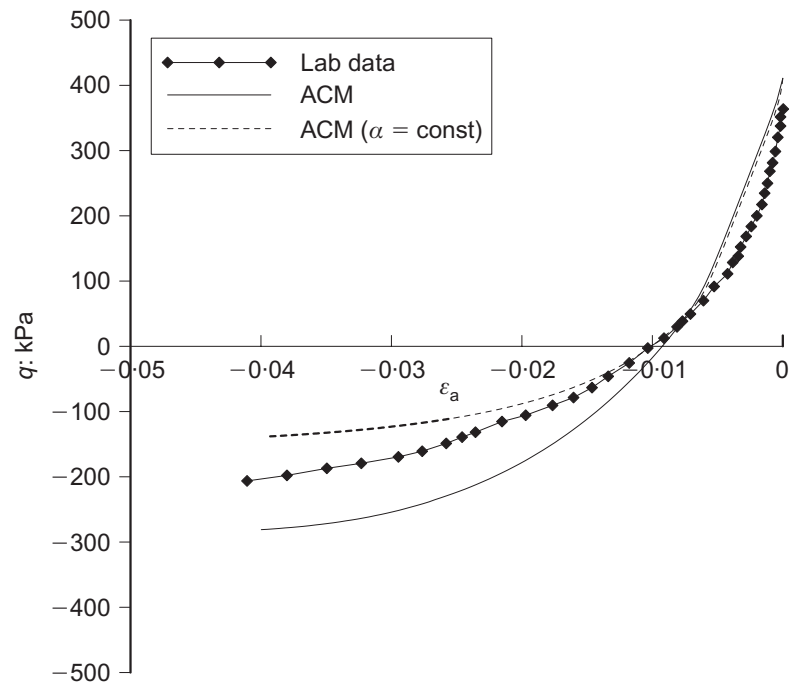

Fig. 14. Hong Kong Marine Deposit: deviatoric stress against axial strain in undrained triaxial compression for test $\mathbf{E 4 0 0}$ (data from Zhou et al., 2006)

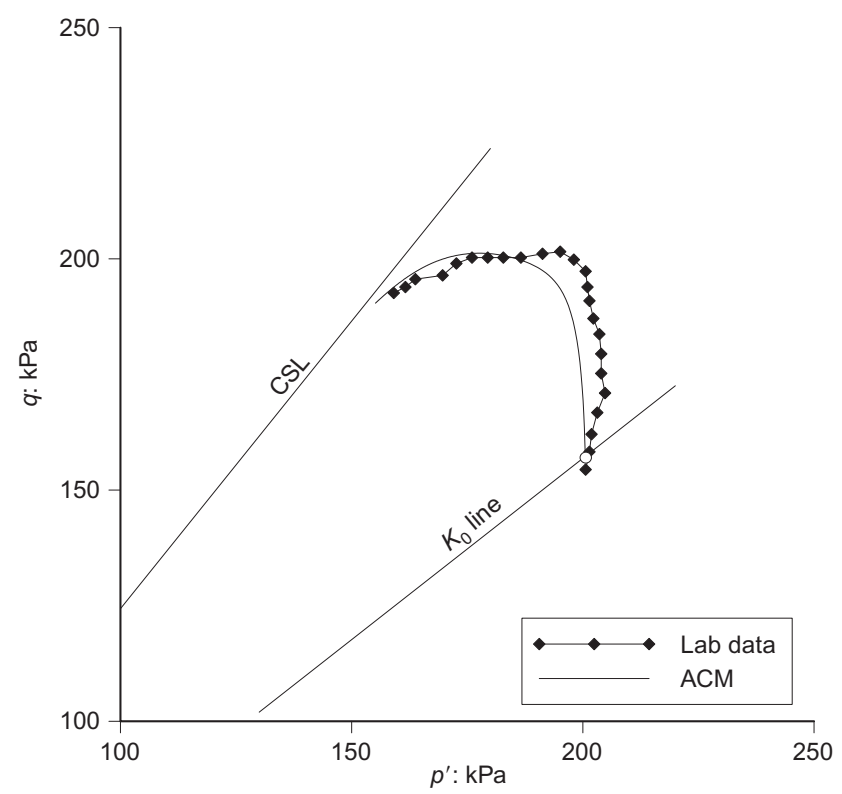

Fig. 15. Hong Kong Marine Deposit: stress path for undrained triaxial compression (data from Zhou et al., 2006)

creep model is able to capture the peak followed by a reduction in deviator stress, clearly shown in the laboratory test, and the slope of the curve of post-peak deviatoric stress against axial strain. The results demonstrate that some of the apparent post-peak softening observed when testing natural soils may be constitutive, rather than a result of localisation and shear banding.

\section{CONCLUSIONS}

In this paper an anisotropic creep model for soft soils is proposed, which accounts for viscous strain-induced anisotropy. First, a complete description of the one-dimensional formulation of the model is given, focusing on the role played by the reference time $\tau$ in defining the normal consolidation surface. The one-dimensional formulation has been extended to a general three-dimensional creep model, in which rotated ellipsoids of the elasto-plastic S-CLAY1 model proposed by Wheeler et al. (2003) are adopted as the 


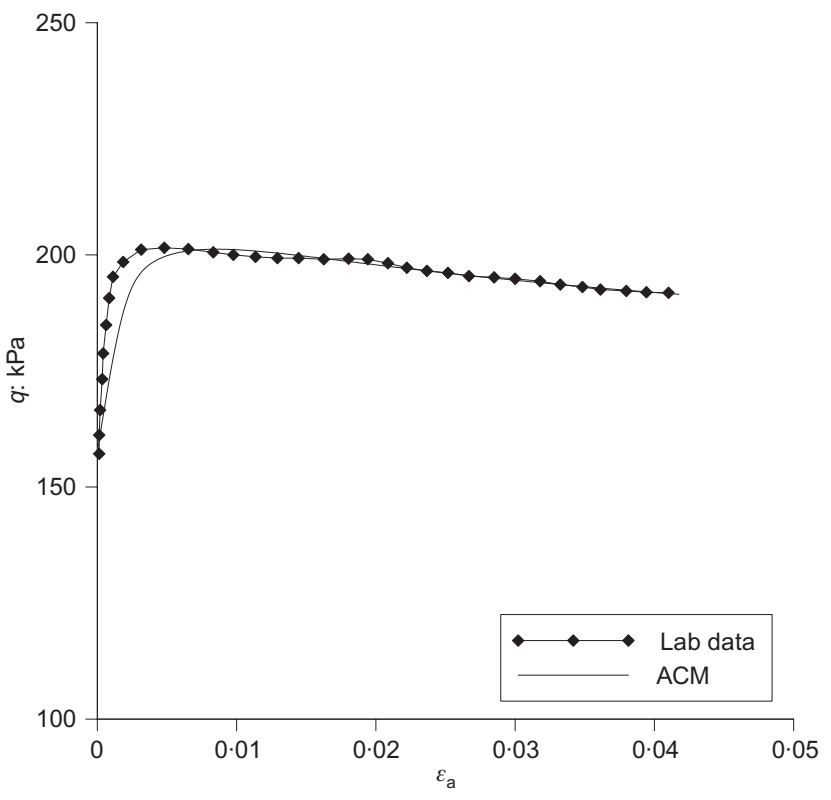

Fig. 16. Hong Kong Marine Deposit; deviatoric stress against axial strain in undrained triaxial compression (data from Zhou et al., 2006)

normal consolidation surface and current stress surface. It is shown that the new model can be considered as both a creep version of S-CLAY1 and an anisotropic enhancement of the isotropic creep model proposed by Vermeer \& Neher (1999). A nice feature of the model is that the additional soil constants as needed for anisotropy can be assessed on the basis of simple correlations with the critical-state friction angle and the modified compression index.

The anisotropic creep model has been implemented in a finite element code, and several validation tests have been performed. In particular, the response of the model in undrained triaxial tests has been compared with the corresponding results obtained with the elasto-plastic S-CLAY1 model, showing a similar behaviour both for the predicted stress path for slow loading rates and for similar rotation of the normal consolidation surface. In order to assess the capability of the model to capture the real behaviour of soft soils, test data of a marine deposit have been used as a benchmark. Undrained triaxial extension test results have been simulated with both the isotropic and the anisotropic creep model, under the same conditions of the laboratory tests. The results show how the isotropic model overestimates the undrained strength of the material whereas, in contrast, the anisotropic creep model gives predictions close to the experimental data. It was also shown that it is necessary to account for changes of anisotropy due to viscous strains to achieve a proper prediction of the undrained shear strength in triaxial extension. Another test was simulated to investigate the behaviour of the model in undrained compression, showing a satisfactory agreement between predictions and measurements.

The improvement in the anisotropic formulation is not limited to a better response in undrained triaxial extension paths. It is well known that the use of Modified Cam Clay ellipses with an associated flow rule implies an overestimation of $K_{0}^{\mathrm{NC}}$. The introduction of anisotropy ensures a realistic prediction of $K_{0}^{\mathrm{NC}}$ while still keeping an associated flow rule, which is very convenient from the numerical point of view. The proposed anisotropic formulation, which accounts for evolution of anisotropy with viscous strains, requires no adjustments to overcome the problem of poor $K_{0}$ predictions, such as a non-associated flow rule (Muir Wood, 1990) or modification of the shape of the yield surface
(Karstunen et al., 2006). In conclusion, the authors feel that the proposed anisotropic model is a significant improvement to the previous isotropic formulation when dealing with soft soils, without requiring any further calibration.

\section{ACKNOWLEDGEMENTS}

The work presented was carried out as part of a Marie Curie Research Training Network 'Advanced Modelling of Ground Improvement on Soft Soils (AMGISS)' (Contract No. MRTN-CT-2004-512120) supported by the European Community through the programme 'Human Resources and Mobility' and the Academy of Finland (grant 210744). The authors would like to thank Professor Y. H. Yin for providing the data for Hong Kong Marine Deposit. The first author is grateful to Dr Ayman Abed and Dr Thomas Benz for fruitful discussions. The authors would also like to thank the anonymous reviewers of the paper for their constructive comments.

\section{NOTATION}

$C_{\mathrm{c}}$ compression index

$C_{i j h k}$ compliance matrix

$C_{\mathrm{S}}$ swelling index

$C_{\alpha}$ creep index

CSS current stress surface

$c_{\mathrm{u}}$ undrained shear strength

$D_{i j h k} \quad$ stiffness matrix

$d$ partial derivative; see equation (38)

$E^{\prime} \quad$ Young's modulus

$e_{0}$ initial void ratio

$\dot{e}$ rate of change of void ratio

$\dot{e}_{\mathrm{nc}}$ rate of change of void ratio for normally consolidated states

$G$ shear modulus

$K_{0} \quad$ lateral earth pressure at rest

$K_{0}^{\mathrm{NC}}$ lateral earth pressure at rest for normally consolidated states

$M$ stress ratio at critical state

$M_{\mathrm{c}}$ stress ratio at critical state in triaxial compression

$M_{\mathrm{e}}$ stress ratio at critical state in triaxial extension

NCS normal consolidation surface

OCR vertical overconsolidation ratio

$\mathrm{OCR}^{*}$ generalised overconsolidation ratio $\left(=p_{\mathrm{p}}^{\prime} / p_{\mathrm{eq}}^{\prime}\right)$

$\mathrm{OCR}_{\mathrm{eoc}}$ OCR at end of primary consolidation

$p^{\prime}$ mean effective stress

$p_{\text {eq }}^{\prime} \quad$ equivalent mean stress

$p_{\mathrm{p}}^{\prime}$ preconsolidation pressure as defined in Fig. 5

$q$ deviatoric stress

$t$ time

$\alpha$ inclination of CCS and NCS in $q / p^{\prime}$ plane

$\alpha_{x}$ component of fabric tensor ( $x$ direction)

$\alpha_{y}$ component of fabric tensor ( $y$ direction)

$\alpha_{z}$ component of fabric tensor ( $z$ direction)

$\alpha_{0}$ initial inclination in $q / p^{\prime}$ plane

$\alpha_{\mathrm{d}}$ deviatoric fabric tensor

$\beta$ creep exponent

$\dot{\gamma}^{\mathrm{c}}$ deviatoric creep strain rate

$\delta_{i j} \quad$ Kronecker's delta

$\dot{\varepsilon}$ strain rate tensor

$\varepsilon_{\text {vol }}^{\mathrm{c}}$ volumetric creep strain

$\dot{\varepsilon_{\mathrm{vol}}^{\mathrm{c}}}$ volumetric creep strain rate

$\eta$ stress ratio $\left(=q / p^{\prime}\right)$

$\eta_{0}$ stress ratio corresponding to $K_{0}$ state

$\kappa^{*}$ modified swelling index

$\Lambda$ plastic multiplier

$\lambda^{*}$ modified compression index

$\mu^{*}$ modified creep index

$v^{\prime}$ Poisson's ratio

$\sigma^{\prime}$ effective stress

$\dot{\sigma}^{\prime}$ rate of change of effective stress

$\sigma_{\mathrm{d}}$ deviator stress tensor 
$\sigma_{\mathrm{p}}^{\prime} \quad$ preconsolidation stress

$\dot{\sigma}_{\mathrm{p}}^{\prime} \quad$ rate of change of preconsolidation stress

$\tau$ reference time

$\tau^{*} \quad$ (creep) time shift

$\phi_{\mathrm{cv}}^{\prime} \quad$ friction angle at critical state

$\omega$ rate of rotation

$\omega_{\mathrm{d}}$ rate of rotation by deviator strains

\section{APPENDIX. EQUATIONS OF ANISOTROPIC CREEP MODEL}

The normal consolidation surface is defined as $p_{\mathrm{eq}}^{\prime}=p_{\mathrm{p}}^{\prime}$, where $p_{\mathrm{p}}^{\prime}$ is a preconsolidation pressure as defined in Fig. 5. The formulation of $p_{\mathrm{eq}}^{\prime}$ is identical to that first suggested by Dafalias (1986), which was adopted for the elasto-plastic model S-CLAY1 (Wheeler et al., 2003), and can be expressed as

$$
p_{\text {eq }}^{\prime}=p^{\prime}+\frac{3}{2 p^{\prime}} \frac{\left\{\sigma_{\mathrm{d}}-p^{\prime} \underline{\alpha}_{\mathrm{d}}\right\}^{\mathrm{T}}\left\{\sigma_{\mathrm{d}}-p^{\prime} \underline{\alpha}_{\mathrm{d}}\right\}}{M^{2}-\frac{3}{2}\left\{\underline{\alpha}_{\mathrm{d}}\right\}^{\mathrm{T}}\left\{\underline{\alpha}_{\mathrm{d}}\right\}}
$$

where the deviatoric stress tensor is defined as $\sigma_{\mathrm{d}}=\sigma^{\prime}-p^{\prime} \delta_{i j}$ and the deviatoric fabric tensor is defined as $\alpha_{d}=\alpha-\delta_{i j}$, where the components have a property $\left(\alpha_{x}+\alpha_{y}+\alpha_{z}\right) / \widetilde{3}=1$. The scalar parameter $\alpha$, which defines the inclination of the normal consolidation surface in simplified triaxial stress space, is defined as

$$
\alpha=\sqrt{\frac{3}{2}\left\{\alpha_{\mathrm{d}}\right\}^{\mathrm{T}}\left\{\alpha_{\mathrm{d}}\right\}}
$$

The rotational hardening law, describing the evolution of the fabric tensor with creep strains, is expressed in the general form as

$$
\dot{\alpha}_{\mathrm{d}}=\omega\left[\left(\frac{3 \sigma_{\mathrm{d}}}{4 p^{\prime}}-\alpha_{\mathrm{d}}\right) \dot{\varepsilon}_{\mathrm{vol}}^{\mathrm{c}}+\omega_{\mathrm{d}}\left(\frac{\sigma_{\mathrm{d}}}{3 p^{\prime}}-\underline{\alpha}_{\mathrm{d}}\right) \dot{\gamma}^{\mathrm{c}}\right]
$$

An associated flow rule is chosen, thus giving the direction of viscous strain rate as

$$
\dot{\varepsilon}_{i j}^{\mathrm{c}}=\Lambda \cdot \frac{\partial p_{\mathrm{eq}}^{\prime}}{\partial \sigma_{i j}^{\prime}}
$$

where the viscous multiplier $\Lambda$ is defined as

$$
\Lambda=\frac{\dot{\varepsilon}_{\mathrm{vol}}^{\mathrm{c}}}{d} \quad \text { with } \quad d=\frac{\partial p_{\mathrm{eq}}^{\prime}}{\partial p^{\prime}}
$$

Volumetric creep strain rate is assumed as

$$
\dot{\varepsilon}_{\mathrm{vol}}^{\mathrm{c}}=\frac{\mu *}{\tau} \cdot\left(\frac{\mathrm{p}_{\mathrm{eq}}^{\prime}}{p_{\mathrm{p}}^{\prime}}\right)^{\beta} \text { with } \mu *=\frac{C_{\alpha}}{\ln 10} \cdot \frac{1}{1+e_{0}} \text { and } \beta=\frac{C_{\mathrm{c}}-C_{\mathrm{s}}}{C_{\alpha}}
$$

Equations (38) and (39) can be inserted into the flow rule (equation (37)) to obtain

$$
\dot{\varepsilon}_{i j}^{\mathrm{c}}=\frac{\mu^{*}}{d \cdot \tau}\left(\frac{p_{\mathrm{eq}}^{\prime}}{p_{\mathrm{p}}^{\prime}}\right)^{\beta} \frac{\partial p_{\mathrm{eq}}^{\prime}}{\partial \sigma_{i j}^{\prime}}
$$

The total strain rate is the sum of an elastic and a viscous part, i.e. $\dot{\varepsilon}_{i j}=\dot{\varepsilon}_{i j}^{\mathrm{e}}+\dot{\varepsilon}_{i j}^{\mathrm{c}}$.

The elastic part of the strains is modelled by Hooke's law

$$
\dot{\varepsilon}_{i j}^{\mathrm{e}}=C_{i j h k} \dot{\sigma}_{h k}^{\prime} \quad \text { or } \quad \dot{\sigma}_{i j}^{\prime}=D_{i j h k} \dot{\varepsilon}_{h k}^{\mathrm{e}}
$$

where

$$
D_{i j h k}=\frac{2 G v^{\prime}}{1-2 v^{\prime}} \delta_{i j} \delta_{h k}+G\left(\delta_{i k} \delta_{j h}+\delta_{i h} \delta_{j k}\right)
$$

with the effective Poisson's ratio $v^{\prime}$ assumed to be a constant.

The shear modulus $G$ is expressed as a function of the modified swelling index $\kappa^{*}$ by the equations

$$
G=\frac{E^{\prime}}{2\left(1+v^{\prime}\right)} \quad \text { and } \quad E^{\prime}=\frac{3 p^{\prime}\left(1-2 v^{\prime}\right)}{\kappa^{*}}
$$

\section{REFERENCES}

Adachi, T. \& Oka, F. (1982). Constitutive equations for normally consolidated clay based on elastoviscoplasticity. Soils Found. 22, No. 4, 57-70.

Adachi, T. \& Okano, M. (1974). A constitutive equation for normally consolidated clay. Soils Found. 14, No. 4, 55-73.

Anandarajah, A., Kuganenthira, N. \& Zhao, D. (1996). Variation of fabric anisotropy of kaolinite in triaxial loading. J. Geotech. Engng 122, No. 8, 633-640.

Bai, X. \& Smart, P. (1996). Change in microstructure of kaolin in consolidation and undrained shear. Géotechnique 47, No. 5, 1009-1017.

Bjerrum, L. (1967). Engineering geology of Norwegian normallyconsolidated marine clays as related to settlements of buildings. Géotechnique 17, No. 2, 81-118.

Boudali,M. (1995). Comportement tridimensionnel et visqueux des argiles naturelles. $\mathrm{PhD}$ thesis, Université Laval, Québec.

Buisman, A. S. (1936). Results of long duration settlement tests. Proc. 1st Int. Conf. Soil Mech. Found. Engng, Cambridge 1, 103-107.

Dafalias, Y. F. (1986). An anisotropic critical state soil plasticity model. Mech. Res. Commun. 13, No. 6, 341-347.

Dafalias, Y. F., Manzari, M. T. \& Papadimitriou, A. G. (2006). SANICLAY: simple anisotropic clay plasticity model. Int. J. Numer. Anal. Meth. Geomech. 30, No. 12, 1231-1257.

Den Haan, E. J. (1996). A compression model for non-brittle soft clays and peat. Géotechnique 46, No. 1, 1-16.

Garlanger, J. E. (1972). The consolidation of soils exhibiting creep under constant effective stress. Géotechnique 22, No. 1, 71-78.

Hanzawa, H. (1989). Evaluation of design parameters for soft clays as related to geological stress history. Soils Found. 29, No. 2, 99-111.

Karstunen, M., Wiltafsky, C., Krenn, H., Scharinger, F. \& Schweiger, H. F. (2006). Modelling the stress-strain behaviour of an embankment on soft clay with different constitutive models. Int. J. Numer. Anal. Meth. Geomech. 30, No. 10, 953-982.

Kulhawy, F. H. \& Mayne, P. W. (1990). Manual of estimating soil properties for foundation design. Ithaca, NY: Cornell University.

Leroueil, S. (1987). Tenth Canadian Geotechnical Colloquium: Recent developments in consolidation of natural clays. Can. Geotech. J. 25, No. 1, 85-107.

Leroueil, S. (2006). The isotache approach. Where are we 50 years after its development by Professor Suklje? Proc. 13th Danube Eur. Conf. on Geotechnical Engineering, Ljubljana, 1, 55-58.

Leroueil, S., Kabbaj, M., Tavenas, F. \& Bouchard, R. (1985). Stress-strain-strain rate relation for the compressibility of sensitive natural clays. Géotechnique 35, No. 2, 159-180.

Liingaard, M., Augustesen, A. \& Lade, P. V. (2004). Characterization of models for time-dependent behavior of soils. Int. J. Geomech. 4, No. 2, 157-177.

Malvern, L. E. (1951). The propagation of longitudinal waves of plastic deformation in a bar of metal exhibiting a strain rate effect. J. Appl. Mech. 18, No. 2, 203-208.

Mesri, G. \& Choi, Y. K. (1985a). Settlement analysis of embankments on soft clays. ASCE J. Geotech. Engng 111, No. 4, 441464.

Mesri, G. \& Choi, Y. K. (1985b). The uniqueness of the end-ofprimary (EOP) void ratio-effective stress relationship. Proc. 11th Int. Conf. Soil Mech. Found. Engng, San Francisco 2, 587-590.

Mesri, G. \& Feng, T. W. (1986). Discussion, 'Stress-strain-strain rate relation for the compressibility of sensitive natural clays'. Géotechnique 36, No. 2, 283-287.

Muir Wood, D. (1990). Soil behaviour and critical state soil mechanics. Cambridge: Cambridge University Press.

Näätänen, A., Wheeler, S. J., Karstunen, M. \& Lojander, M. (1999). Experimental investigation of an anisotropic hardening model for soft clays. Proc. 2nd Int. Symp. on Pre-failure Deformation Characteristics of Geomaterials, Turin, 541-548.

Norton, F. H. (1929). Creep of steel at high temperatures. New York: McGraw-Hill.

Nova, R. (1982). A viscoplastic constitutive model for normally consolidated clays. Proc. IUTAM Conf. on Deformation and Failure of Granular Materials, Delft, 287-295.

Perzyna, P. (1966). Fundamental problems in viscoplasticity. In Advances in Applied Mechanics (ed. G. Kuerti), vol 9. New York: Academic Press, 243-377.

Pestana, J. M. \& Whittle, A. J. (1999). Formulation of a unified 
constitutive model for clays and sands. Int. J. Numer. Anal. Meth. Geomech. 23, No. 12, 1215-1243.

Sekiguchi, H. \& Ohta, H. (1977). Induced anisotropy and time dependency in clays. Proc. 9th Int. Conf. Soil Mech. Found. Engng, Tokyo, Spec. Session 9, 229-238.

Stolle, D. F. E., Bonnier, P. G. \& Vermeer, P. A. (1997). A soft soil model and experiences with two integration schemes. Proc. NUMOG VI, Montreal, 123-128.

Suklje, L. (1957). The analysis of the consolidation process by the isotaches method. Proc. 4th Int. Conf. Soil Mech. Found. Engng, London, 1, 200-206.

Vaid, Y. \& Campanella, R. G. (1977). Time dependent behaviour of undisturbed clay. ASCE J. Geotech. Engng 103, No. 7, $693-$ 709.

Vermeer, P. A. \& Neher, H. P. (1999). A soft soil model that accounts for creep. Proceedings of the international symposium 'Beyond 2000 in Computational Geotechnics', Amsterdam, pp. 249-261.

Vermeer, P. A., Stolle, D. F. E. \& Bonnier, P. G. (1998). From the classical theory of secondary compression to modern creep analysis. Proc. Computer Methods and Advances in Geomechanics, Wuhan, China 4. Rotterdam: Balkema, 2469-2478.

Wheeler, S. J., Näätänen, A., Karstunen, M. \& Lojander, M. (2003). An anisotropic elastoplastic model for soft clays. Can. Geotech. J. 40, No. 2, 403-418.

Yin, J.-H. \& Graham J. (1999). Elastic viscoplastic modelling of the time dependent stress-strain behaviour of soils. Can. Geotech. J. 36, No. 4, 736-745.

Yin, J.-H. \& Cheng, C.-M. (2006). Comparison of strain-rate dependent stress-strain behavior from $K_{0}$-consolidated compression and extension tests on natural Hong Kong marine deposits. Mar. Geores. Geotech. 24, No. 2, 119-147.

Zentar, R., Karstunen, M. \& Wheeler, S. (2002). Influence on anisotropy and destructuration on undrained shearing of natural clays. Proc. Numer. Methods Geotech. Engng NUMGE 2002. Paris: ENPC/LCPC Press.

Zhou, C., Yin, J.-H., Zhu, J.-G. \& Cheng, C.-M. (2006). Elastic anisotropic viscoplastic modeling of the strain-rate dependent stress-strain behaviour of $K_{0}$-consolidated natural marine clays in triaxial shear test. Int. J. Geomech. 5, No. 3, 218-232. 